Revista Arbitrada Interdisciplinaria de Ciencias de la Salud. SALUD Y VIDA

Volumen 4. Número 7. Año 4. Enero - Junio 2020

Hecho el depósito de Ley: FA2016000010 ISSN: 2610-8038

FUNDACIÓN KOINONIA (F.K)

Santa Ana de Coro, Venezuela.

Lenys Piña-Ferrer

http://dx.doi.org/10.35381/s.v.v4i7.670

\title{
EI COVID 19: Impacto psicológico en los seres humanos
}

COVID 19: Psychological impact on humans

\author{
Lenys Piña-Ferrer \\ dralenysp@gmail.com \\ Universidad Privada Dr. Rafael Belloso Chacín, Maracaibo \\ Venezuela \\ https://orcid.org/0000-0002-9493-7499
}

Recibido: 1 de marzo de 2020

Aprobado: 2 de abril de 2020

\section{RESUMEN}

El estudio se desarrolló con el propósito de analizar los impactos psicológicos que produce el COVID 19 en los seres humanos. Es una investigación de carácter analítica, exploratoria con diseño documental, bibliográfico, a fin de comprender el significado y efectos que produce en los individuos esta enfermedad. Entendiendo que los individuos al ser sometidos a situaciones de incertidumbre por lo general, presentan reacciones de diverso índole psicológico. En cuanto a sus resultados por ser una enfermedad contagiosa es importante la educación no solo por parte de los organismos del Estado sino también de los miembros del grupo familiar y del paciente en si para evitar caer en estados depresivos o síntomas estresores puesto que los mismos pueden durar desde meses hasta años.

Descriptores: Estrés mental; efectos psicológicos; salud mental; política de la salud.

\section{ABSTRACT}

The study was developed with the purpose of analyzing the psychological impacts that COVID 19 produces in human beings. It is an analytical, exploratory research with documentary, bibliographic design, in order to understand the meaning and effects that this disease produces in individuals. Understanding that individuals, when subjected to situations of uncertainty, generally present reactions of diverse psychological nature. Regarding its results, as it is a contagious disease, it is important to educate not only the state agencies but also the members of the family group and the patient itself to avoid falling into depressive states or stressful symptoms since they can last from months to years.

Descriptors: Mental stress; psychological effects; mental health; health policy. 


\section{INTRODUCCIÓN}

En el mundo contemporáneo la palabra "crisis" produce impacto, incertidumbre, reacción y surgen con ello una serie de interrogantes entre las cuales tenemos ¿Cómo evolucionar ante ella? ¿Cómo asumirla? ¿Cómo enfrentarla? ¿A qué riesgos estaré sometido? ¿Cuáles serán sus efectos económicos? ¿Sociales? ¿Culturales? ¿Emocionales? ¿De qué manera nos afectara como personas? ¿A nosotros y a nuestro entorno más cercano?

Pues bien iniciemos diciendo que hoy por hoy el mundo, está atravesando por una crisis en cuanto a la pandemia denominada "Coronavirus" o como su nombre científico lo reseña la Organización Mundial de la Salud (OMS) COVID-19 o SARS-CoV-2, por ello importante destacar que para responder a tantas interrogantes que se presentan en estos momentos, la mejor vacuna es "la información", pero una información certera, verdadera, que lleve intrínseco el valor científico y profesional que ello representa.

Ante ello es de sumo interés conocer cómo reacciona la mente humana sometida ante un bombardeo de información sobre el tema que si se quiere es de gran alarma mundial, de hecho, las cifras por países así lo indican. En primer lugar, se hace necesario buscarle el lado positivo al asunto que estamos viviendo, verle las buenas acciones de las personas, los gestos de solidaridad, apoyo, manifestaciones de afecto con nosotros y hacia nuestro grupo familiar.

Es por ello que en la actualidad pueden verse profesionales con comportamientos que dejan ver el grado de lealtad, ética, entrega, dedicación en cuerpo y alma por ayudar, apoyar, sin descanso a todo aquel que de verdad lo necesita, la gran mayoría dejan a un lado sus familias por dedicarle horas a su prójimo, incluso hasta ceder espacios físicos dedicados para otros fines, esta vez lo hacen para fines humanitarios. Todo ello buscando primero tratar de brindar ese equilibrio emocional que hace falta para luego interceder en la parte medica propiamente. Conozcamos un poco de que se trata.

\section{COVID 19.}

Según lo reseña el Manual de la MSD (2020) "es una enfermedad respiratoria aguda, a veces grave, causada por un nuevo coronavirus SARS-CoV2". Reseña de igual 
manera el documento citado que los primeros casos de COVID-19 se relacionaron con un mercado de animales vivos en Wuhan, China, lo que sugiere que el virus se transmitió inicialmente de los animales a los seres humanos. La diseminación de persona a persona se produce a través del contacto con secreciones infectadas, principalmente a través del contacto con gotitas respiratorias grandes, pero también podría ocurrir a través del contacto con una superficie contaminada por gotitas respiratorias; no se sabe con certeza si la infección se puede contraer por vía fecaloral o qué papel desempeñan los aerosoles (pequeñas gotitas respiratorias) en la transmisión. Tampoco se sabe con certeza con qué facilidad se propaga este virus de persona a persona o cuál será la sostenibilidad de la infección en una población, aunque parece más transmisible que SARS y la propagación es probablemente más similar a la de la gripe.

Por su parte en relación a los signos y síntomas señala el Manual de la MSD (2020) que las personas con COVID-19 pueden tener pocos síntomas o ninguno, aunque algunas enferman gravemente y mueren. Los síntomas pueden consistir en fiebre, tos y disnea. Los pacientes con enfermedad más grave pueden presentar linfopenia y hallazgos en las imágenes de tórax compatibles con neumonía. No se sabe con certeza cuál es el tiempo exacto de incubación; las estimaciones van de 1 a 14 días. Las estimaciones según lo reseña el manual de la tasa de mortalidad inicial procedentes de China (2,3\% en la serie de casos más amplia) indican que parece menos grave que el SARS (10\%) o el MERS (35\%); la mortalidad aumenta con la edad.

Los superdifusores desempeñaron un papel extraordinario en la conducción del brote de SARS de 2003 y también pueden desempeñar un papel importante en el brote actual de COVID-19. Un superdifusor es un individuo que transmite una infección a un número significativamente mayor de personas que un individuo infectado promedio. Se están aplicando medidas de cuarentena y aislamiento en un intento por limitar la propagación local, regional y global de este brote.

Otra definición importante es la expresada por Muñoz (2020) en la Revista Geosalud cuando indica que los coronavirus son una extensa familia de virus que pueden causar enfermedades leves como el resfriado común, y enfermedades graves como el SRAS 
(síndrome respiratorio agudo severo) o el síndrome respiratorio de Oriente Medio (MERS-CoV), y más recientemente el nuevo coronavirus identificado en la ciudad china de Wuhan, este nuevo virus fue nombrado oficialmente como SARS-CoV-2, además el nombre oficial de la enfermedad provocada por el nuevo virus es "COVID19" según la Organización Mundial de la Salud.

Reseña de igual manera el autor que, los coronavirus llevan su nombre por las puntas en forma de corona que tienen en su superficie. Los coronavirus humanos comunes que la mayoría de las personas contraen en algún momento de sus vidas, incluyen los siguientes tipos:

- 229E (coronavirus alfa)

- NL63 (coronavirus alfa)

- OC43 (coronavirus beta)

- HKU1 (coronavirus beta)

Se observa entonces en lo descrito en párrafos anteriores la reseña científica y médica del fenómeno en estudio, sin embargo, en todo lo expuesto puede detallarse como dejan a un lado la parte psicológica y emocional de los individuos, aspecto que considero de sumo interés ante la situación que se está viviendo hoy día. Pasemos entonces a hacer otras definiciones y aspectos teóricos a considerar

\section{Hipocondría Social}

En palabras de Britez, Torrales, Valenzuela y Chávez (2012) la hipocondría fue definida como la preocupación por el miedo a tener, o la creencia de que se tiene, una enfermedad física grave basándose en la interpretación errónea de síntomas corporales. Si bien útil, consideramos que esta definición planteó una serie de dificultades, principalmente relacionadas a la integridad del concepto de hipocondría y a su separación de otros trastornos.

Asimismo autores como Ferguz, Diez y Barsky citados por Torrales (2017) sugirieron la presencia de una serie de componentes esenciales en la hipocondría siendo nucleares los dos primeros: 1) convicción de enfermedad; 2) miedo a la enfermedad; 3) preocupación corporal (atención focalizada, interés y vigilancia sobre funciones y 
sensaciones corporales); 4) síntomas somáticos; y 5) conductas hipocondríacas (comprobaciones repetidas sobre la salud, incluyendo el diagnóstico y la búsqueda de tranquilización).

Revisando lo expuesto por los autores citados anteriormente puede verse que en la actualidad son muchas las personas que están padeciendo esta enfermedad por cuanto es tanto el temor que representa la misma que sin tener el virus o ningún tipo de factor que pueda representar riesgo de contagio, ya por el simple hecho de escuchar diferentes tipos de informaciones ya sienten los síntomas y es lo que se denomina hipocondría social.

Asimismo, señala Ferguz (2010) que, en referencia a lo expuesto, se deben destacar dos características distintivas entre la convicción de enfermedad y la fobia a la enfermedad: (a) Variables de percepción corporal (amplificación somatosensorial), que son propias de la fobia a la enfermedad, pero no de la convicción de enfermedad; y, (b) Disregulación emocional (evitación y revaloración cognitiva), que es predictora de la convicción de enfermedad y no de la fobia a la enfermedad. Por otra parte, una característica común entre fobia y convicción de enfermedad, es que ambas predicen una utilización incrementada de recursos médicos. De allí entonces surge la necesidad que las personas o individuos ante la presencia o no de este virus lo primero que se debe atender es la estabilidad emocional para poder enfrentarse al mismo.

También es importante señalar lo expuesto por Starcevic (2014) cuando indica que en los últimos años el término hipocondría comenzó a recibir significativos cuestionamientos, en relación a lo planteado a continuación por lo que la Asociación Americana de Psiquiatría (2013) decidió eliminarlo con base a tres principales razones:

- La hipocondría es un término anticuado y etimológicamente se refiere a una alteración abdominal, lo que lo hace obsoleto y completamente alejado de su concepción actual;

- La hipocondría es un concepto heterogéneo, que contiene dos principales componentes, como se mencionó previamente más arriba: convicción de enfermedad y miedo a la enfermedad. Esta estructura ha sido problemática en 
pacientes con presentaciones clínicas diversas que han recibido la misma etiqueta diagnóstica; $y$,

- El término hipocondría ha sido considerado peyorativo y estigmatizante.

Indica también el autor citado que la quinta edición del Manual Diagnóstico y Estadístico (DSM-5) de la Asociación Americana de Psiquiatría (2013) introdujo dos trastornos nuevos para reemplazar a la hipocondría: el trastorno de síntomas somáticos y el trastorno de ansiedad por enfermedad. Los autores del DSM-5 determinaron, de una manera un tanto arbitraria, que el $75 \%$ de los pacientes con un diagnóstico de hipocondría (según el DSM-IV de 1994) recibiría ahora el diagnóstico de trastorno de síntomas somáticos, mientras que el $25 \%$ restante recibiría el de trastorno de ansiedad por enfermedad. La diferencia clave entre estos dos "nuevos" trastornos se basa en que síntomas somáticos, disruptivos y angustiantes están presentes en el trastorno de síntomas somáticos, mientras que están ausentes o sólo mínimamente $(5,7)$ presentes en el trastorno de ansiedad por enfermedad.

\section{METODOLOGÍA}

La metodología implementada para el desarrollo de este estudio, considera en sus argumentos los diferentes factores los cuales involucran al entorno social y junto con este a los individuos, quien en definitiva son los determinantes de las técnicas que se utilizan para el análisis de los datos obtenidos. De esta manera, se puede contextualizar el conocimiento de forma explícita, sin embargo, es importante considerar que el presente artículo se hizo de manera analítica, exploratoria reflexivo el cual según Hernández, Fernández y Baptista (2014) son aquellos cuando el objetivo es examinar un tema o problema de investigación poco estudiado o que no ha sido abordado antes.

Es decir, cuando la revisión de la literatura reveló que únicamente hay guías no investigadas e ideas vagamente relacionadas con el problema de estudio, o bien, si deseamos indagar sobre temas y áreas desde nuevas perspectivas, en el caso particular por considerar que la temática de estudio se encuentra en pleno auge y que no se pueden dar cifras ni datos exactos por cuanto aún persiste la pandemia. 
Asimismo, el diseño fue documental, bibliográfico para ello Sabino (1996) los diseños de carácter bibliográficos posibilitan al investigador cubrir una amplia gama de fenómenos, por cuanto no sólo debe basarse en los hechos a los cuales él mismo tiene acceso, sino que puede extenderse para abarcar una experiencia inmensamente mayor y señala algunas tareas básicas:

- Conocer y explorar todo el conjunto de fuentes capaces de sernos de utilidad. Estas fuentes fueron libros, artículos científicos, revistas, publicaciones y boletines diversos, y en general toda la rica variedad de material escrito que frecuentemente puede encontrarse sobre un tema.

- Se realizó un arqueó de todas las fuentes disponibles.

- Se recolectan los datos y los aspectos concretos de cada fuente que fueron de utilidad en la investigación.

- Se ordena la información de acuerdo a los contenidos con el objeto de especificar el esquema del reporte final.

- Se compara y analiza la información.

- Se obtienen las conclusiones correspondientes.

Además de ello señala Tamayo y Tamayo (2012:70) Cuando recurrimos a la utilización de datos secundarios, es decir, aquellos que han sido obtenidos por otros y nos llegan elaborados y procesados de acuerdo con los fines de quienes inicialmente los elaboran y manejan, se dice que es un diseño bibliográfico.

\section{RESULTADOS}

\section{Impacto psicológico ante el aislamiento}

Sobre el particular señala la Revista Infocop Online (2020) del Consejo General de la Psicología de España que ante el brote de epidemia por coronavirus COVID19/SARS-CoV-2 ha provocado que muchos países pidan a las personas que han estado en contacto con la infección se aíslen en su hogar, bajo vigilancia domiciliaria. También es importante destacar que ante esta situación y en virtud de la expansión ante los demás países el resto de las personas por igual deben de permanecer aislados para evitar que se siga propagando la enfermedad generando en ellos 
desesperación, perdida de libertad, aburrimiento, insomnio, poca concentración e indecisión, irritabilidad, ira, ansiedad, angustia, de no tener contacto físico con familiares, amigos, no poder desarrollar una rutina de vida normal, todo ello puede traer consigo efectos dramáticos sino son bien canalizados. Todos ellos considerados factores altamente estresores y contraproducentes para el ser humano portador o no del COVID19.

De la misma manera se hace necesario mencionar algunos factores estresores durante y después de la cuarentena que inciden de manera notoria en el individuo tal como lo señalan Brooks, S.K., Webster, R.K., Smith, L.E., Woodland, L., Wessely, S., Greenberg, N., Rubin, G.J. (2020):

- Duración de la cuarentena: una mayor duración de la cuarentena se asocia específicamente con una peor salud mental, síntomas de estrés postraumático, conductas de evitación e ira.

- Miedo a la infección: ocurre en los individuos ante algún temor a la epidemia propiamente y a poder contagiar a miembros de su grupo familiar, manifestándose en cualquier síntoma de la enfermedad.

- Frustración y aburrimiento: ocurre cuando las personas se encuentran e aislamiento y no pueden realizar su rutina diaria, quedando reducida el contacto con los demás miembros que por lo general se rodea, además de las actividades diarias que realiza: compras, trabajo, entre otras.

- Suministros inadecuados: esto genera gran impacto sobre todo en personas acostumbradas a tener satisfechas sus necesidades básicas, las mismas van asociadas con frustración, ansiedad, y enfado propiamente.

- Información inadecuada: muchas personas afirman que la información por parte de las autoridades de salud pública es escasa, contradictoria y supone un factor estresante, al ofrecer insuficientes pautas sobre los pasos a seguir y crear confusión sobre el propósito de la cuarentena.

- La falta de claridad sobre los diferentes niveles de riesgo, concretamente, lleva a las personas a temer lo peor. Igualmente, se informa de una percepción de falta de transparencia por parte de los funcionarios de salud y del Gobierno 
sobre la gravedad de la pandemia, quizás relacionado con la ausencia de pautas claras o justificación.

- De la misma manera es importante mencionar según lo reseñan los autores citados algunos factores estresores tras la cuarentena:

- Economía: la pérdida financiera puede ser un problema durante la cuarentena, ya que las personas no pueden trabajar y tienden a desequilibrarse económicamente sin una planificación previa, esto crea un nivel de angustia, ira, ansiedad que pone en juego la salud emocional de los individuos, causando daños psicológicos incluso por varios meses después de la cuarentena.

- Es por ello que aquellas personas con niveles de ingresos más bajo, tienden a verse mayormente afectadas mostrándose así con estados depresivos más severos, que incluso se hace necesario tratarse con un profesional, es importante que en los lugares de trabajo los empleadores puedan apoyar este tipo de situaciones con programas, talleres $u$ otras herramientas hacia sus empleados.

- Estigma: por lo general el ser humano considera el estigma como factor de rechazo ante cualquier situación que se le pueda presentar, en el caso específico por tratarse de la cuarentena ya lo consideran sinónimo de miedo, sospecha, tratan de manera diferente. Es por ello que la educación sobre la epidemia es tan importante como la justificación de la misma y evitar así la menos estigmatización posible.

\section{REFLEXIONES FINALES}

Ante la reflexión de la temática de estudio y viendo de manera detallada la problemática. Es de interés hacer algunas recomendaciones para mitigar el impacto psicológico causado por la pandemia del COVID 19. Entre ellas se tiene:

Por ser una enfermedad contagiosa es importante la educación no solo por parte de los organismos del estado sino también de los miembros del grupo familiar y del paciente en si para evitar caer en estados depresivos o síntomas estresores puesto que los mismos pueden durar desde meses hasta años. 
Restringir la duración de la cuarentena a lo que es científicamente razonable de manera de evitar lo menos posible los traumas que éste genera. Para las personas que ya están en cuarentena, una ampliación de esta situación, por pequeña que sea, puede exacerbar cualquier sensación de frustración o desmoralización.

Sensibilizarse internamente de los riesgos que tiene la enfermedad de manera de poder transmitir los mismos a su entorno familiar de manera consciente, y así poder tomar la situación de manera más ligera.

\section{Brindar a las personas toda la información disponible.}

Prestar apoyo a las personas en cuanto a suministros de alimentos, medicamentos entre otros siempre y cuando no interfiera en su salud emocional y física.

Reducir el aburrimiento y mejorar la comunicación con los miembros del grupo familiar con actividades en conjunto de manera de sentirse apoyado, si no se puede hacer de manera directa, pues se hace por medio de las redes sociales de manera de aliviar un poco los factores estresantes.

Estar atentos a las redes sociales sobre las informaciones actualizadas del tema, así podrán verificar las posibles soluciones al mismo.

Contar con una línea de asistencia telefónica, atendida por profesionales de la salud mental, específicamente para aquellos/as en cuarentena podría ser eficaz, al ofrecerles una red social.

El poder comunicarse con la familia y los/as amigos/as también es esencial: las redes sociales pueden desempeñar un papel importante en la comunicación con aquellos/as que se encuentran lejos, permitiendo que las personas en cuarentena actualicen a sus seres queridos sobre su situación y les aseguren que están bien. Esto podría reducir la sensación de aislamiento, estrés y pánico.

En relación a los profesionales de la salud, es importante el apoyo del equipo de trabajo de manera de no sentirse estigmatizado por alguno de los miembros del paciente afectado o en su defecto por sus mismos colegas. Ellos merecen una atención especial.

De igual modo es importante reconocer y hacer ver a las personas la importancia que tiene ser solidario con el resto al momento de hacer la cuarentena voluntaria, esto 
permitirá mantener la seguridad, la lealtad y el apoyo minimizando así los efectos psicológicos que pueden generarse producto de la enfermedad.

También es importante comunicarles a las personas "como mantenerse a salvo" con las personas que conviven, es decir es la información clara la mejor vacuna ante esta enfermedad. Con educación lo podemos lograr.

Dependiendo de la forma como se maneje la situación se podrá tener éxito tanto las autoridades sanitarias como el resto de los miembros involucrados.

\section{REFERENCIAS CONSULTADAS}

1. American Psychiatric Association, edited. Diagnostic and statistical manual of mental disorders. 5th ed. Arlington: APA; 2013.

2. Brítez J, Torales J, Valenzuela C, Chávez ME (2012). Trastornos somatomorfos. En: Arce Ramírez A, Torales Benítez J, editores. El libro azul de la psiquiatría. Asunción: EFACIM; 2012. p. 185-204.

3. Brooks, S.K., Webster, R.K., Smith, L.E., Woodland, L., Wessely, S., Greenberg, N., Rubin, G.J. (2020). El impacto psicológico de la cuarentena y cómo reducirlo, según un estudio. Revista Infocop Online del Consejo General de la Psicología de España.

4. Fergus TA, Valentiner DP. (2010) Disease phobia and disease conviction are separate dimensions underlying hypochondriasis. J Behav Ther Exp Psychiatry. 2010; 41(4): 438-44.

5. Hernández, Fernández y Baptista (2016).Metodología de la Investigación. 6ta Edición. Mac Graw.Hill.

6. Jiménez, A (2020). Consejos para el estado de alarma: Confinamiento y salud mental: cómo acatar la medida desde el mejor punto de vista psicológico. ConSalud.es

7. Manual MSD (2020). Versión para profesionales de la medicina. El mejor lugar para consultar primero para recibir información médica. Disponible en https://www.msdmanuals.com/es-ve/professional

8. Muñoz, C (2020). ¿Qué es el Coronavirus?. Revista Geosalud. Su sitio de salud en la web. Disponible en: https://www.geosalud.com/enfermedades_infecciosas/sindrome-respiratoriocoronavirus-oriente-medio/coronavirus.html 
9. Organización Mundial de la Salud (2020). Infecciones por coronavirus.Disponible https://www.who.int/csr/don/archive/disease/coronavirus_infections/es/

10. Starcevic V. (2014) Should we deplore the disappearance of hypochondriasis from DSM-5? Aust N Z J. Psychiatry. 2014; 48(4): 373-4.

11. Tamayo, M (2012). El proceso de investigación científica. Mexico. Limusa.

12. Torrales, J (2017). ¡Ayúdeme doctor, estoy muy enfermo! Una actualización de la clásica hipocondría al vigente trastorno de ansiedad por enfermedad. Rev. virtual Soc. Parag. Med. Int. marzo 2017; 4 (1):77-86 